\title{
Pros, cons and future perspectives - three questions on three dimensional guidance for cardiac catheterization in congenital heart disease
}

\author{
Sebastian Góreczny ${ }^{1,2}$, Gregor Krings ${ }^{3}$, Ziyad M. Hijazi ${ }^{4}$, Thomas Fagan ${ }^{5}$, Darren Berman ${ }^{6}$, Damien Kenny ${ }^{7,8}$, \\ Gareth J. Morgan²
}

${ }^{1}$ Department of Cardiology, Polish Mother's Memorial Hospital, Research Institute, Lodz, Poland

2Department of Cardiology, Colorado Children's Hospital, Aurora, Colorado, USA

${ }^{3}$ Pediatric Heart Center, Utrecht, Netherlands

${ }^{4}$ Department of Pediatrics, Weill Cornell Medicine and Sidra Heart Center, Doha, Qatar

${ }^{5}$ Cleveland Clinic Children's Hospital, Lerner College of Medicine, Cleveland, USA

${ }^{6}$ The Heart Center, Nationwide Children's Hospital, Columbus, Ohio, USA

${ }^{7}$ Our Ladies Children's Hospital, Dublin, Ireland

${ }^{8}$ The Mater Misericordiae University Hospital, Dublin, Ireland

Adv Interv Cardiol 2019; 15, 3 (57): 263-273

DOI: https://doi.org/10.5114/aic.2019.87688

\begin{abstract}
Step changes in angiographic imaging are not commonplace. Since the move from analogue to digital and flat detector plates, two-dimensional imaging technology has certainly evolved but not jumped forward. Of all the routine imaging techniques used in cardiology, angiography has been the last modality to embrace the third dimension. Although the development of rotational angiography was initially for the benefit of neuroimaging and fusion of cross sectional datasets was aimed at the treatment of descending aortic pathology, interventional physicians in congenital and structural cardiology have immersed themselves in this technology over the last 10 years. Like many disruptive technologies, its introduction has divided opinion. We aimed to explore the mindset of those in the field of interventional cardiology who are driving imaging forward. These structured interviews recorded during the $21^{\text {st }}$ Pediatric and Adult Interventional Cardiac Symposium illustrate the challenges and sticking points as well as giving an insight into the direction of travel for three-dimensional imaging and fusion techniques. Covering a wide range of career development, seniority and experience, the interviewees in this article are probably responsible for the majority of the published literature on invasive three-dimensional imaging in congenital heart disease.
\end{abstract}

Key words: cardiac imaging, fusion imaging, percutaneous treatment, congenital heart defects.

\section{Introduction}

Step changes in angiographic imaging are not commonplace. The last major advance was probably the move from analogue to digital and flat detector plates in the 1980s and early 90s [1, 2]. Since then, two-dimensional (2D) imaging technology has certainly evolved but not jumped forward. All the time we have been conscious of the need to minimize exposure to ionizing radiation and ionic contrast whilst improving the accuracy of our data and integrating it with modern cross-sectional techniques such as computed tomography (CT), magnetic resonance imaging (MRI) and three-dimensional (3D) echocardiography [3-8]. Of all the routine imaging techniques used in cardiology, angiography has been the last modality to embrace the third dimension [5]. Although the development of rotational angiography (Figure 1) was initially for the benefit of neuroimaging and fusion of cross sectional datasets (Figure 2) was aimed the treatment of peripheral vascular pathology, interventional physicians in congenital cardiology have immersed themselves in this technology over the last 10 years [918]. Like many disruptive technologies, its introduction has divided opinion. Cost, benefit, radiation and contrast exposure have fed the natural resistance to change and 

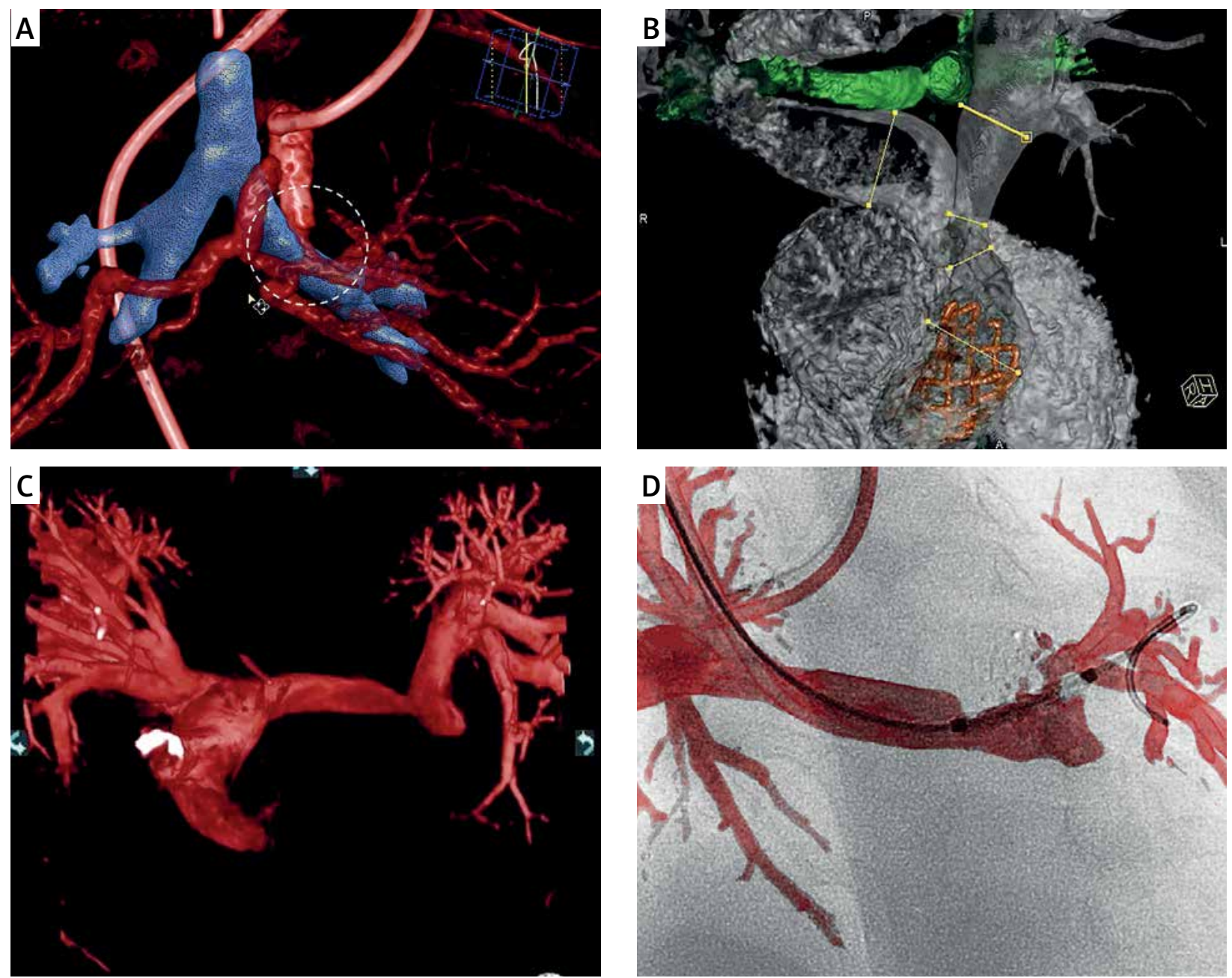

Figure 1. Cutting edge examples of three-dimensional rotational angiography (3DRA). Panel A uses simultaneous vessel and airway segmentation from 3DRA to illustrate a complex spatial interaction (white dashed circle) between the aorto-pulmonary collaterals (red) and the left main bronchus (blue). Similarly, panel B presents relationship between the pulmonary arteries (gray) and the airways (green). Three-dimensional reconstruction from rotational angiography provides unlimited views not achievable with a standard angiography such as in panel $\mathbf{C}$ where the pulmonary arteries are being visualized from what is effectively a 90 cranial view. Overlaying the 3D model onto live fluoroscopy can then serve as a roadmap for guidance of device positioning and deployment (D). Panels A courtesy of Dr Jenny Zablah, Colorado Children's Hospital, Aurora, Colorado, USA, panel B courtesy of Dr Gregor Krings, Pediatric Heart Center, Utrecht, Netherlands

whilst the potential harm is low the benefits have also been difficult to quantify [18-21].

Dr. Sebastian Goreczny, Assistant Professor of Pediatric Cardiology at the Polish Mother's Memorial Hospital, used part of his time as a Fulbright Senior Award scholar at the Children's Hospital of Colorado to explore the mindset of those in our field who are driving imaging forward. These structured interviews recorded during the $21^{\text {st }}$ Pediatric and Adult Interventional Cardiac Symposium (PICS, November 2018) illustrate the challenges and sticking points as well as giving an insight into the direction of travel for 3D imaging and fusion techniques. Covering a wide range of career development, seniority and experience, the interviewees in this article are probably responsible for the majority of the published literature on invasive 3D imaging in congenital heart disease [18-32]. They each collaborate with a broad range of industry partners to map out the future direction of invasive imaging with specific reference to our complex patient group.

Senior key opinion leaders in paediatric and congenital heart disease tend to be innovative disruptive thinkers, but interestingly adoption of newer imaging technologies has been focused among those in the first half of their faculty career. Drs Berman, Kenny, Morgan and Góreczny are spurred on by the support and drive of more senior faculty like Drs Krings, Fagan and Hijazi. They are breaking their moulds whilst we construct ours. 

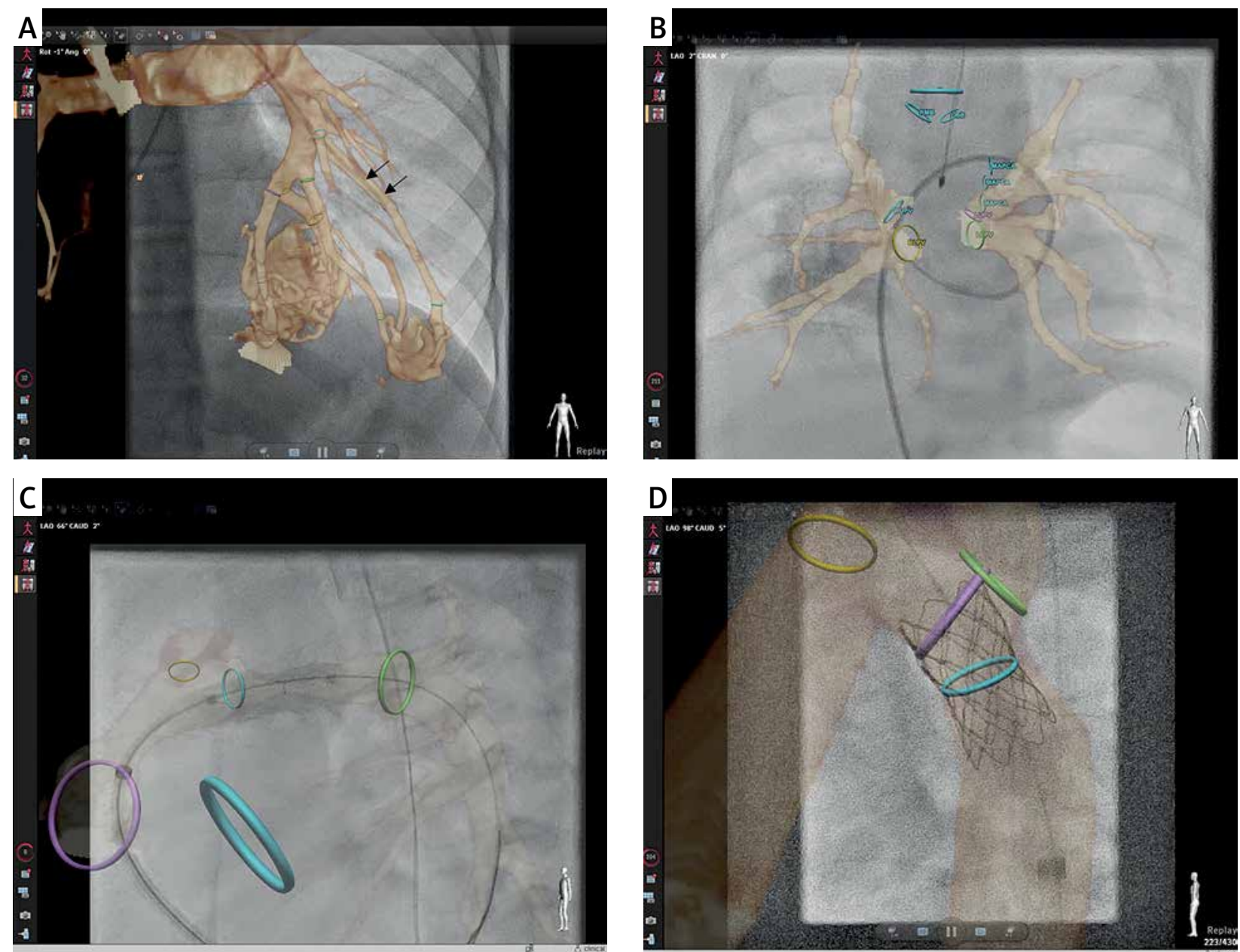

Figure 2. Examples of fusion of non-invasive three-dimensional imaging, computed tomography or magnetic resonance, with two-dimensional fluoroscopy. In selected patients with very accurate alignment of the 3D roadmap, reduction or even elimination of contrast injection for device positioning if feasible. Panel $\mathbf{A}$ demonstrates how a 3D roadmap can facilitate selection and intubation of the desired branch in a patient with multiple pulmonary arterio-venous malformations. An overlay of a 3D reconstruction is used to guide catheter introduction to the right upper pulmonary vein in a patient with pulmonary vein stenosis (B). Three-dimensional overlay with additional marking rings indicating stent landing zone guide stenting of a proximal left pulmonary (C) and coarctation of the aorta (D) stenting

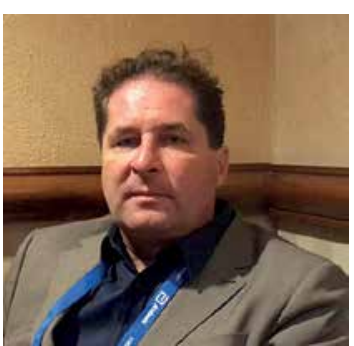

Dr. Gregor Krings Head of Pediatric Heart Center, Utrecht, Netherlands

Sebastian Goreczny: Please tell us about your experiences with 3D guided catheterizations.

Gregor Krings: With the new imaging system at the Heart Center in Utrecht, introduced in 2011, we had the opportunity to start with this 3DRA technique. Our experience so far is some $700-800$ cases over the last years $[19,20$, 30-32]. From the interventions we do in our institution
I would say that probably $70-80 \%$ are based on 3DRA or imported previous CTs. It's easier to say which interventions I would not do with 3D guidance, which would be atrial septal defect (ASD) closure, pulmonary and aortic valve dilations. For everything else, including pulmonary vein stenosis, pulmonary artery stenosis, percutaneous pulmonary valve implantation (PPVI), aortic stenosis, and sometimes complex ventricular septal defects (VSD), I would use 3D guidance.

Sebastian Goreczny: From your experiences what are the current benefits of 3D guided catheterizations?

Gregor Krings: If you adapt your workflow to the optimum, meaning putting the radiation output of your system down by really customizing it, if you optimize your workflow by doing multiple location injections, then first 
you can bring down the radiation which you would use in a typical congenital heart procedure. Second, you would bring down the total amount of contrast (although the single amount of contrast in the 3D rotation is bigger), in total you would reduce contrast necessary for angiography. The third, which is the most important thing, I would call "defocus". Typically, in the old biplane way to get a stent in a branch pulmonary artery, you would visualize the branch and put the stent in and you would be done. What I mean, it defocuses and if you look at the topography of the chest in a 3D way you would really understand the surroundings, and the neighboring structures of your target. You would recognize if the bronchus is in the way, the pulmonary veins are in the way or if the space under the aortic arch is limited. When you have a 3D rotational work station you don't necessarily have to perform 3DRA but you're always able to work with all kinds of 3D data. Since 3DRA does create images as computed tomography (CT) stacks which are very comparable to CT, you can, at these work stations use CT as well as $3 D$ rotations which were performed previously in the patient. There are intrinsic benefits you have once you know these techniques, capable of importing or working with 3D imaging, you can better understand topography with an acquired 3D rotation or take the understanding which you had from a CT done previously and bring this imaging with your understanding of a substrate to a case and use it to project this 3D image to your black and white biplane angiography. It will combine understanding of the patient's substrate which you had prior to the case with everything you acquired with high end imaging during the case. This gives a very high level of safety for the patient because you understand the whole topography, so the benefit to understand the topography means that possible damage would not happen because you would understand what to look for. In biplane you would not be able to look for the airway in the way it is necessary to stent the left pulmonary artery (LPA), but if you were to do this with the $3 \mathrm{D}$ rotational or imported CT you could look which size of stent would keep the left bronchus open $[13,32]$. The benefit of this procedure is safety, it is safe radiation if you tune your system and optimize it from the vendor settings and customize it to optimum level $[20,21]$. So it's safety, reduced radiation, you would do it all in one run and then post process the whole entire chest structure contrasted. You would not do multiple angiographies to look for collaterals and next to safety and radiation reduction you have many other benefits. You could save time if your team is in a good workflow and your workflow is adapted to all the needs, then you will save time because in one acquisition you will have all the information. If you are an interventionist, then your thinking is very much target oriented, very focused, when you start to work with 3D imaging, which is really a new area for yourself, then you will be forced and have the opportunity to start to work with different work stations and work with 3D images on these work stations, which will widen up your horizon and give you inside views, which you wouldn't have if you only did biplane caths.

\section{Sebastian Goreczny: What are the limitations of current 3D guidance for cardiac catheterizations?}

Gregor Krings: I think the major limitations are that the four vendors which sell the systems don't have an adequate way to bring the technique to the client. The biggest limitations result from the nonexistence of protocols, how to do 3D, the vendors don't tell you how to do 3D. The system settings are really not optimized for congenital cases. This is one of the shortcomings that really start at the beginning. Another limitation with techniques is that the 3D overlay is fixed and does not follow anatomical movements. Another limitation is that if you use any kind of roadmap, biplane or 3D, and after bringing the roadmap to the screen, introduced long sheaths, stiff wires result in the shift of anatomy (Figure 3) which cannot be handled by the roadmap image you used. Another limitation is that although you work with DICOM data which is universal, the vendors keep their systems closed up so that they are not really openly communicating with other vendors' 3D rotational systems. So if you had a 3D dataset form Philips, it would not be necessarily reproducible on Siemens or Toshiba the same way. This is the vendors' policy, that restricts sharing of experiences. At this moment rotational angiography is acquired with an anterior-posterior (AP) camera over $5 \mathrm{~s}$. With biplane acquisition we could bring down the acquisition time to $2.5 \mathrm{~s}$, which would require half of the contrast. It would be nice to be able to project the $3 \mathrm{D}$ image on the biplane camera or projector because right now it's only an AP projection of the $3 \mathrm{D}$ roadmap and biplane would be necessary. A jump in the future will be that the static characteristic used as a roadmap should be and could be changed to be a dynamic 3D image, which we know from magnetic resonance imaging (MRI) [33]. If the current efforts to do 4D rotational angiography (4DRA) would become part of a clinical tool, it would be nice to have a moving 3D dataset. It would enable realistic measurements or judgments on large right ventricular outflow tracts (RVOTs), changes in any kinds of structures due to pulsatility and you could take care of it.

\section{Sebastian Goreczny: What will be the role of 3D guidance for the next 5-10 years?}

Gregor Krings: The role and the aim should be that there's no intervention dealing with stents or valves or major devices that would be done without 3D. This will be the target, the vision, this will be my aim because I think I am proving that this 3D technique will enhance safety and the inside view and reduce radiation. The role 

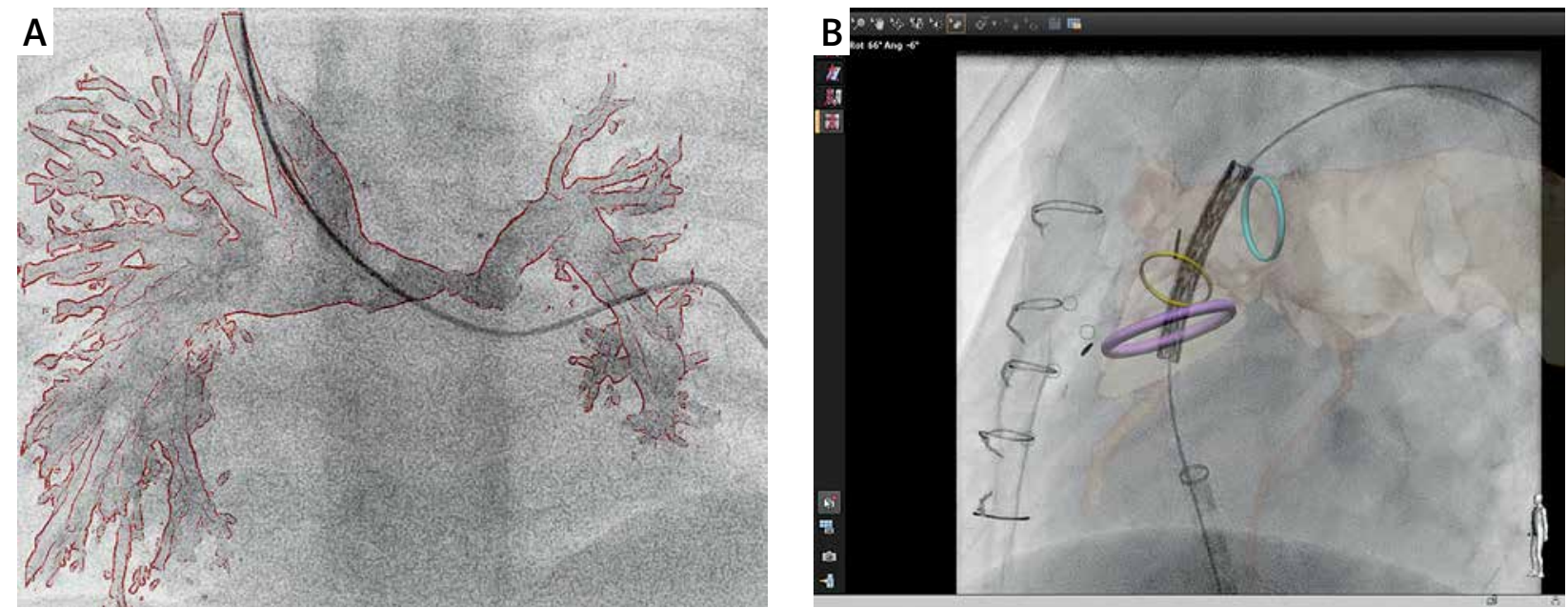

Figure 3. Examples of current limitations of three-dimensional (3D) guidance for cardiac catheterization. All currently available technologies provide "rigid registration", which does not compensate for cardiac and respiratory motion as well as vessel distortion which can occur with the introduction of stiff equipment. Panel A illustrates how introduction of a standard 0.035 " guidewire to the left pulmonary artery resulted in a significant mismatch between the 3D rotational angiography roadmap and the actual position of the pulmonary artery. Similarly, during prestenting for a percutaneous pulmonary valve implantation, panel B shows how introduction of a stiff guide wire and balloon/stent assembly led to a significant misalignment between the fused computed tomography roadmap and the live fluoroscopic position of the pulmonary arteries (B)

of 3D guided interventions I think is to enhance safety and reduce radiation, to create the inside view of an entire topography and to stop treating the LPA as the pulmonary artery only, it is in the surrounding of a very complex infrastructure where lymphatics, pulmonary veins, aorta are all around. The role will be to go back to what you learned during studying, the body is a very complex infrastructural crossing of many, many structures and it doesn't work to focus on just one. The role will be to enlarge your understanding of the substrate, the lesion you will tackle and the role will be to integrate different modalities into your workflow because otherwise an echocardiographer would ignore the MRI knowledge, or the $M R I$ radiologist would ignore the surgeon's view, etc. One of the roles of 3D/4D in the future will be to collaborate to bring real multimodality for daily use.

Sebastian Goreczny: Thank you. Gregor Krings: Thank you.

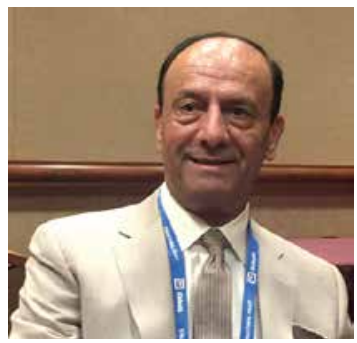

Prof. Ziyad M. Hijazi Chairman of Department of Pediatrics and Director at Sidra Heart Center, Doha, Qatar

Sebastian Goreczny: Tell us about your experiences with 3D guided catheterizations.
Ziyad M. Hijazi: With 3D printing, we have been doing this for a few years, initially on rare occasions, for complicated cases, we obtain the DICOM images via CT and send them to Belgium and they'll do it. For the last year in Doha, we have purchased our own 3D printer and have been using it more often for even simple cases. I believe and I have said it during the PICS three or 4 years ago that any program involved in congenital and structural interventions should have access to a 3D printer (whether that is your own or you send the images to someone and they do it). It helps you plan the intervention, you can visualize where the defect or lesion is and then plan the intervention [34, 35]. There was an article about a year ago about the sinus venosus atrial septal defect and partial anomalous venous drainage closure; now more and more people are doing catheter intervention in such cases and it is crucial to have the $3 \mathrm{D}$ printed model there, put the stent inside the model, so you see that the pulmonary vein is not occluded and it drains back to the left atrium and so forth [36, 37]. So, I think 3D printing is really crucial there.

Now, 3D angiography, when I was in Chicago our angio suite was a Toshiba model. I was doing 3DRA on almost all the cases. It is so helpful, we saw during the 3D symposium (The International Symposium on 3D Imaging for Interventional Catheterization in CHD) at PICS how important and crucial an assessment of various things is, from branch pulmonary arteries and coronary arteries, to planning valve deployment in the RVOT, where the proximity of the coronary arteries is so important; only with the rotational angiography will 
you see the real proximity of the coronary arteries to the RVOT [38-41].

Sebastian Goreczny: From your perspective could you list the benefits of 3D guided catheterizations?

Ziyad M. Hijazi: All of us, especially the old-timers, who have not used this technology at all, we just want conventional angiography. It's similar to the introduction of ultrasound guided puncture; some say "I don't need it", but comfort in these things make you use it more and more. As an interventional cardiologist, I would love to have access, all the time, to 3D guided images to do my intervention. Now, do we do this all the time? No, sometimes because of the time it takes to get the image, because of the overdrive pacing to get better visualization; and it is all a little bit cumbersome. I am asking from the manufacturers, all of them, to continue refining the technology. Make it so easy so that we don't have to go through all of this rapid right ventricular pacing, and over five seconds, six seconds, the total amount of contrast and all of this. But, having it, it's fantastic.

\section{Sebastian Goreczny: What are the main limitations of current 3D guided techniques?}

Ziyad M. Hijazi: The limitations are that they are just cumbersome and the preparation to do it; the room, the table, the anesthesiologist, holding breath, rapid pacing, all of these are a nuisance. Of course they are not a big enough deal to break from the technology, but I think we are getting used to it. But if we don't have to do all that and can do it in a simpler way, I think that's good.

Number two is the issue of the contrast, the amount of contrast, because in one injection you need to give about $1-2 \mathrm{ml} / \mathrm{kg}$, but if you want to do an intervention, sometimes you have to repeat the injection after. So, maybe the contrast load would be slightly more. We have seen that people are overcoming this by giving less and less contrast.

Sebastian Goreczny: What do you think will be the role of 3D guided catheterizations in the next 5-10 years?

Ziyad M. Hijazi: I think every lab is going to have it, no question about it. What we have seen, the advancement from 3D guided intervention to holography, cinematic views, this is phenomenal [42-44]. It's a great technology. You've got to start with 3D and take it from there. Over the next few years I think we will see more and more catheterization labs around the world acquiring systems that provide them with the 3D technology so that you can look at things in many different views. Again, there are certain views that you can get with 3D rotation you would not be able to get with 2D at all. This is important for the interventionalist.

Sebastian Goreczny: Thank you.

Ziyad M. Hijazi: Thank you.

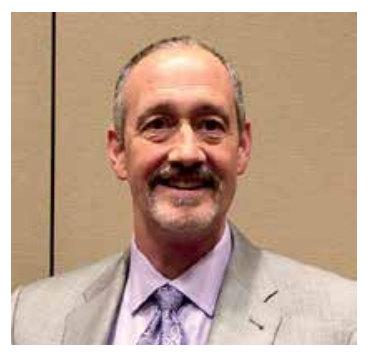

\author{
Dr. Thomas Fagan \\ Medical Director for Pedi- \\ atric Congenital Cardiac \\ Catheterization Lab - \\ Cleveland Clinic Children's \\ Hospital, Lerner College of \\ Medicine, Cleveland, USA
}

Sebastian Goreczny: Could you tell us about your experiences with 3D guided catheterizations?

Thomas Fagan: I started using systems for 3D guidance fairly early, mostly working with a specific company that started with not such simple equipment, and actually took quite a long time, especially with 3DRA, to reconstruct images and then be able to use those for overlay guidance [22, 23, 25-27, 29]. It was very cumbersome, time intensive, added a fair amount of time to procedures. Thankfully, everything has progressed well from there. I think we worked hard enough with it and helped prove the concept. We helped show the utility of having the overlay guidance to facilitate the procedures and to actually make them a little bit more safe. At least the operators felt more comfortable with device delivery and positioning and from there everything has moved forward well enough. The systems are much more simple, especially for 3DRA. There are newer technologies for use of other modalities such as MRI, CT and transesophageal echo fusion that have been developed, and especially the Siemens system and the Philips VesselNavigator are quite user friendly [45-54]. Hopefully as we continue to develop programs utilizing these technologies it will make our procedures much simpler for the operator. One of the main goals is to reduce radiation exposure in total for the patient, and I think we're showing that at least use of these technologies does not add radiation $[17,50]$. We have a long way to go to optimize these techniques as we're still new in this realm. Work by many including yourself, you've done quite a lot of work in this space especially as one of the pioneers with the Philips VesselNavigator System experience, will hopefully continue to make our interventions much more patient friendly $[17,41,45-49,51,54]$.

\section{Sebastian Goreczny: From your experiences what are} the current benefits of 3D guided catheterizations?

Thomas Fagan: I think we've shown that the folks that spend the time to go through the learning curve with these products, and now they're becoming less steep learning curves, feel much more comfortable with the interventions. They actually feel that it can optimize the procedures in such a way that it can reduce the time of the procedure, cut down on radiation and gives a much better feeling of procedural control. Considering that fluoroscopy does not really show the soft tissue anatomy of the heart and vasculature, knowing anatomical details and locations guided by these overlay images gives 
greater confidence during our interventions. You can visualize where those devices are going to go and where our catheters are being manipulated. It gives a better sense of confidence for the operator and that translates to greater safety for the patients.

\section{Sebastian Goreczny: What are the current limitations of 3D guided techniques?}

Thomas Fagan: There are still several. In the case of 3DRA, we still need to work to reduce radiation exposure. None of these modalities, with the exception of echocardiographic fusion, are real-time [4-8]. It's one point in time we generate these images, then we overlay them during the procedure. If something happens to move the patient, or we distort the anatomy with delivery systems, the systems do not track these anatomic changes. Most times the fused 3D images are still of benefit even with these anatomic distortions, though not optimally. At times these anatomic changes make fusing imaging of limited utility. Typically, you can work through it, but these are still clear limitations. One advantage for the echocardiographic fusion is that some systems are real-time. Other downsides, especially for the import of $\mathrm{MRI}$ and other 3D datasets, is that registration still tends to be a bit cumbersome in a lot of regards. The VesselNavigator system, which I haven't used clinically, tends to be much easier, but there are still challenges with registering and maintaining that registration through the case. Those are things that hopefully can continue to be improved upon. There are systems that are being developed to track some of the movements of the heart during these procedures, not necessarily real-time, so that we can adjust for some distortion [55].

Sebastian Goreczny: What will be the role of 3D guided catheterizations in the next $5-10$ years?

Thomas Fagan: The main role still will be to improve the safety and efficacy of performing the procedures. Mostly we're trying to cut down on procedural time, contract dose and radiation exposure. As we continue to move forward, hopefully we can continue these improvements. The way I look at it, this is just the tip of the iceberg for what will be a change in how we perform these interventions. People since the 1980s, and the advent of echocardiography, have said diagnostic cardiac catheterization is going to go away and that we don't need it anymore, because we have all these non-invasive or less-invasive modes of imaging. Well, this is 2018, diagnostic cardiac catheterization is still very strong, so it won't go away in the near future, but there are ways and modes to keep moving forward using guidance technologies that actually will reduce use of ionizing radiation and at some point we will move away from it completely.

Sebastian Goreczny: Thank you.

Thomas Fagan: Thank you.

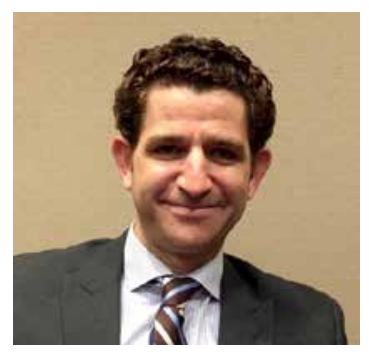

Dr. Darren Berman Pediatric Interventional Cardiologist Nationwide Children's Hospital in Columbus, Ohio, US

Sebastian Goreczny: Tell us about your experiences with 3D guided catheterizations.

Darren Berman: Three-dimensional guidance in the cath lab can be a number of different things, but my experience with 3D guided catheterizations includes 3D ultrasound assessment with transesophageal echocardiography (TEE) and intracardiac echocardiography (ICE) as well as rotational angiography [56]. A single rotational angiogram provides an informative $3 \mathrm{D}$ reconstruction of your image, cross sectional CT-like information, and in addition to that, the ability to overlay or fuse the $3 \mathrm{D}$ image onto live fluoroscopy to try and help guide us. Three-dimensional rotational angiography is something that I started using very early on, beginning in my training and then really through my years as an interventional cardiologist. I've been using it as an extra tool, or an important tool in the cath lab, going back 8 years now. Really the best way to think about 3DRA is as an excellent adjunctive tool to biplane angiography to really allow us to image complex heart structures in the cath lab.

\section{Sebastian Goreczny: From your experiences what are} the current benefits of 3D guided catheterizations?

Darren Berman: There are multiple ways to answer that. In the cath lab, we are imaging complex congenital heart defects, which many times can be complex 3D structures. For the longest time we have used two cameras or biplane imaging to understand a 3D structure. Three-dimensional rotational angiography allows us to obtain a 3D reconstruction of complex 3D structures and in that way help us better understand complex cardiovascular structures. A single 3DRA can be looked at and manipulated on a computer to help guide the rest of the procedure. It can tell us the best angles to perform conventional biplane angiography and sometimes may allow to proceed with an intervention using a single plane only. Not only does it help us to understand the 3D structure more completely, I think it starts to explain to us mechanisms of a stenosis that we may see. The cross sectional CT dataset allows us to see surrounding structures more clearly and understand the relationship between them and the heart itself.

Sebastian Goreczny: What are the limitations of current 3D guided techniques?

Darren Berman: Personally, I think the biggest limitations to 3DRA is it requires people to buy into the fact that 
there may be a new way to look at something and then when and how to incorporate that into their procedures in the cath lab. I think the technology is limited because not enough people are asking how can 3DRA become part of their routine imaging for a procedure. I don't think there has been as much buy in as I was hoping for; I think still that the minority of pediatric interventional cardiologists use the technology.

\section{Sebastian Goreczny: What do you think should} happen, what should vendors provide us with so that more people will start using this technology?

Darren Berman: I think they need to provide the necessary resources for cath labs to be properly trained. Someone builds a new cath lab, there's built in training for all the buttons and the buttonology. What to push, how to make your cameras go here, how to make your cameras go there, how to make your measurements on your angiograms. I think there needs to be a dedicated team within that to be able to teach $3 \mathrm{D}$ rotational angiography to the whole cath lab team. Maybe that requires having physicians experienced in 3DRA come to sites to help them or consider having a new user go to onsite training with whichever vendor they have to have them teach how to use it properly. I think this needs to be built in to the services that are provided by the specific vendors.

\section{Sebastian Goreczny: What will be the role of 3D} guided catheterizations in the next 5-10 years?

Darren Berman: No one knows for sure, but I think that as those of us that have adopted the technology early, those of us that saw the advantages of it need to continue to work with the technologies and vendors to make the process even more streamlined. We've shown how we can reduce the radiation does from a 3DRA to less than a biplane angiogram, but I think there are people out there that still believe the radiation dose might be too high. So we need to continue to work with the vendors to modify the techniques for acquiring a 3D dataset where it even brings the dose down further. This will only help to continue to show how it can be done safely and effectively and efficiently. In addition to this, fusion overlay of 3D structures onto live fluoroscopy may become a more routine part of some procedures. The system I'm most familiar with is Canon Medical (formerly Toshiba Medical) [24]. They have built in computers and monitors that allow for almost immediate fusion of a 3DRA right onto live fluoroscopy. This essentially allows the operator to be looking at two AP images, one conventional AP image and one with the $3 \mathrm{D}$ reconstruction fused onto the live image. Continuing to develop that technology where the image can be fused with our digital acquisitions and not just with live fluoroscopy will really help guide interventions. Figuring out a way to fuse the image with the lateral detector and not just the AP detector will also enhance this feature [50]. As well as making it more than a 3D fusion. So right now it's a static image on the screen of a live fluoroscopy and we need to get to the point where that's a 4D image, beating heart as we're moving our catheters around on live fluoroscopy [33]. These are just some of the potential future directions of this technology.

\section{Sebastian Goreczny: Thank you. \\ Darren Berman: Thank you.}

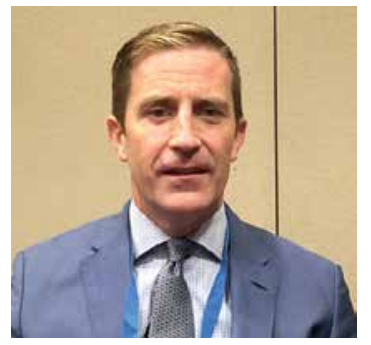

\author{
Dr. Damien Kenny \\ Consultant cardiologist \\ - Our Ladies Children's \\ Hospital and the Mater \\ Misericordiae Univer- \\ sity Hospital, Dublin, \\ Ireland
}

\section{Sebastian Goreczny: Could you tell us about your experiences with 3D guided catheterizations?}

Damien Kenny: I did my fellowship training in the US, in Chicago, and they had a 3DRA there and we used to use it, I suppose infrequently to be honest. I don't think we ever had proper training. So my experience with 3DRA was that it was available to us but we used it infrequently and I'm not sure we used it optimally. More recently since l've come back to Ireland we've had a very experienced and knowledgeable colleague come over and guide us on how to use 3DRA to help guide our interventions. It has been a revelation for us. I think we're using it more appropriately now; I think we're starting to understand the benefits of what it can provide for us. That's my experience, I suppose it's gone from a tool we had available that we used infrequently that showed us nice pictures to something that we actually functionally use in a more meaningful way now.

\section{Sebastian Goreczny: Could you list the benefits of 3D guided catheterizations?}

Damien Kenny: I think it probably gives us greater anatomical detail on the defects we treat. One of the most difficult things for us to decide is whether we're doing the right thing because we're potentially subjecting the patient to some risk with each procedure. Using 3DRA provides a little more assurance that we're performing the appropriate intervention in the optimal manner by providing greater detail regarding the morphology of the lesion. One of the things l've been very impressed about is the extra information regarding extra cardiac structures particularly the airway [13, 32]. We used 3DRA recently on a baby born with hyperplastic last heart syndrome who'd had a LPA stent who also had a re-coarctation of the aorta. We were cognizant with the preexisting stent in the LPA and a further stent in the aorta, we might actually compress the left mainstem bronchus because this had happened 
to us before in this particular anatomy. Three-dimensional rotational angiography clearly showed that had we put the stent in the aorta, we would have compressed the airway. So it's not just about pretty pictures - this was really important functional information to have for this patient. Interestingly, more and more our surgeons like to use CT in our redo sternotomy patients because they want to look at the orientation of the great vessels etc. to the sternum. So they use CT a reasonable amount. The fact that we can provide 3DRA is something that they can glean extra information from and prevent potentially a patient having a CT scan preoperatively, so I think that's an extra additive benefit of 3D in our institution.

\section{Sebastian Goreczny: What are the current limitations of 3D guided techniques?}

Damien Kenny: I would say the greatest limitation is physician engagement - many interventionalists have managed for many years without 3DRA and the effort may seem too great. There is a learning curve with it, I think you have to have patience with it. It takes a little bit of extra time initially, like any new procedure. Sometimes it's not always perfect and there's always a concern that you're giving extra contrast and potentially extra radiation to a patient. I think sometimes still, and I wouldn't regard myself as an expert in the field at all, compared to some other people that have really mastered this, but I do think that there are times where you've done a 3D rotational angiogram and you probably have not optimized, for whatever reason, you still don't understand exactly why the pictures haven't been as good as they should be. I think having that ability to be able to spend time and reflect why your pictures aren't good and be able to change so the next time you get better is something that people maybe don't have the patience to do and I think that's unfortunate. I think establishing it for me, so that it becomes a routine part of your practice, is one of the downsides because we all want to get our procedures done quickly and safely and adding something extra into that takes a bit of time to consider reasons why we would actually take the time to do it.

\section{Sebastian Goreczny: What will be the role of 3D guided catheterizations in the next 5-10 years?}

Damien Kenny: I think because of all of this computing technology it's very hard to say where we are going to be but one of the things I still struggle with is what the intraluminal pathology is, i.e. - what's going on inside a stenotic vessel? We can see on the outside that they look a bit narrow and sometimes it's very clear cut but specifically with complex distal main pulmonary artery and proximal branch pulmonary artery stenosis, I still think it's difficult to know what the vessel looks like inside and once we've done our intervention is it better? That's one of the things that I would like 3D imaging to help us with. Also we need towards understanding the functional consequences of our interventions and what's happening to the physiology of the vessel. We know that abnormal flow patterns affect vessel endothelium in a negative way leading to inflammation. I wonder if we can start to prove that intervention $A$ is better than intervention $B$ not just because it's anatomically better but because it's functionally or physiologically better and if we can get flow patterns from 3DRA that are meaningful I think that's going to be a huge advantage [57]. I think it's a great tool but I'm unsure, in a very positive way, where this is going to end up but I think it's going to be a great story because the technology is already developing rapidly.

\section{Sebastian Goreczny: What are your thoughts on holography, or fusion imaging, or 4D rotational angiography; which of these techniques will lead in the future?}

Damien Kenny: I'm not sure where this will lead us - I'm just not sure how functionally relevant this is going to be. I think the fusion imaging, the concept of having an ability of being able to overlay something and be able to look at it and say this is where we should put the stent, is great [58]. I still don't think we're using it appropriately at the moment, we're still doing side angiograms or hand angiograms for reassurance. The holography thing, I'm still not really sure how it's going to make our interventions safer, quicker, better at this point in time. I think the images are fascinating to look at but I'm just uncertain on where it will be in 10 years time.

\section{Sebastian Goreczny: Do you think now is the time for some of the interventional training to be designated for 3D imaging techniques in the cath lab?}

Damien Kenny: I certainly would advocate for this having had the benefit of having somebody come and spend time in our lab who is an expert in the field. We learned that the hard way, we were doing it and we understood how to do it but not how to optimize the acquisition and interpretation. I think we're seeing the impact of that now because we're using it more appropriately. It's all about proper training [40]. I think the other thing that's relevant for the newer generation of interventionalists is that early exposure and appropriate training is more likely to lead to greater use and development of the technology. I think training is definitely an important thing to have because if we're going to use it we should use it right, I would prefer to use it right or not use it at all.

Sebastian Goreczny: Thank you.

Damien Kenny: Thank you.

\section{Acknowledgments}

Dr. Goreczny would like to thank the Polish-U.S. Fulbright Commission for supporting his research projects with a Senior Award Scholarship. 


\section{Conflict of interest}

G. Krings is a member of the Siemens Advisory Board. The other authors declare no conflict of interest.

\section{References}

1. Dickinson DF, Wilson N, Partridge JB. Digital subtraction angiography in infants and children with congenital heart disease. Br Heart J 1984; 51: 485-91.

2. Spahn M. Flat detectors and their clinical applications. Eur Radiol 2005; 5: 1934-47.

3. Hill KD, Frush DP, Han BK, et al. Image gently alliance. Radiation safety in children with congenital and acquired heart disease: a scientific position statement on multimodality dose optimization from the image gently alliance. JACC Cardiovasc Imaging 2017; 10: 797-818.

4. Jone PN, Ross MM, Bracken JA, et al. Feasibility and safety of using a fused echocardiography/fluoroscopy imaging system in patients with congenital heart disease. J Am Soc Echocardiogr 2016; 29: 513-21.

5. Hascoët S, Warin-Fresse K, Baruteau AE, et al. Cardiac imaging of congenital heart diseases during interventional procedures continues to evolve: pros and cons of the main techniques. Arch Cardiovasc Dis 2016; 109: 128-42.

6. Jone PN, Zablah JE, Burkett DA, et al. Three-dimensional echocardiographic guidance of right heart catheterization decreases radiation exposure in atrial septal defect closures. J Am Soc Echocardiogr 2018; 31: 1044-9.

7. McLennan D, Góreczny S, Jone PN, et al. Left ventricular outflow tract pseudoaneurysm occlusion with fusion of live 3-dimensional transesophageal echocardiography and fluoroscopy. Kardiol Pol 2019; 77: 647-8.

8. Rodríguez-Zanella H, Sandoval JP, García-Montes JA, et al. Echocardiographic-fluoroscopic fusion imaging to guide device occlusion of a complex left ventricle-to-right atrium shunt. Eur Heart J Cardiovasc Imaging 2019; 20: 961.

9. Zahn E. The emerging use of 3-dimensional rotational angiography in congenial heart disease. Congenial Cardiol Today 2011; 9: 1-13.

10. Góreczny S, Dryżek P, Moszura T, et al. Rotational angiography in monitoring of covered CP stent implantation in patient with critical aortic coarctation and patent ductus arteriosus. Kardiol Pol 2012; 70: 505-7.

11. Glöckler M, Halbfa $\beta$ J, Koch A, et al. Multimodality 3D-roadmap for cardiovascular interventions in congenital heart disease: a single-center, retrospective analysis of 78 cases. Catheter Cardiovasc Interv 2013; 82: 436-42.

12. Moszura T, Goreczny S, Dryzek P, Niwald M. Three-year-old child with middle aortic syndrome treated by endovascular stent implantation. Pediatr Cardiol 2013; 34: 1027-30.

13. Borik S, Volodina S, Chaturvedi R, et al. Three-dimensional rotational angiography in the assessment of vascular and airway compression in children after a cavopulmonary anastomosis. Pediatr Cardiol 2015; 36: 1083-9.

14. Goreczny S, Morgan GJ, Dryzek P, et al. Initial experience with live three-dimensional image overlay for ductal stenting in hypoplastic left heart syndrome. Eurolntervention 2016; 12: 1527-33.

15. Goreczny S, Morgan GJ, Dryzek P. Live 3D image overlay for arterial duct closure with Amplatzer Duct Occluder II additional size. Cardiol Young 2016; 26: 605-8.
16. Stenger A, Dittrich S, Glöckler M. Three-dimensional rotational angiography in the pediatric cath lab: optimizing aortic interventions. Pediatr Cardiol 2016; 37: 528-36.

17. Goreczny S, Moszura T, Dryzek P, et al. Three-dimensional image fusion guidance of percutaneous pulmonary valve implantation to reduce radiation exposure and contrast dose: a comparison with traditional two-dimensional and three-dimensional rotational angiographic guidance. Neth Heart J 2017; 25: 91-9.

18. van der Stelt F, Siegerink SN, Krings GJ, et al. Three-dimensional rotational angiography in pediatric patients with congenital heart disease: a literature review. Pediatr Cardiol 2019; 40: 257-64.

19. Manica JL, Borges MS, Medeiros RF, et al. A comparison of radiation dose between standard and $3 \mathrm{D}$ angiography in congenital heart disease. Arq Bras Cardiol 2014; 103: 131-7.

20. Peters $M$, Krings $G$, Koster $M$, et al. Effective radiation dosage of three-dimensional rotational angiography in children. Europace 2015; 17: 611-6.

21. Minderhoud SCS, van der Stelt F, Molenschot MMC, et al. Dramatic dose reduction in three-dimensional rotational angiography after implementation of a simple dose reduction protocol. Pediatr Cardiol 2018; 39: 1635-41.

22. Schwartz JG, Neubauer AM, Fagan TE, et al. Potential role of three-dimensional rotational angiography and $\mathrm{C}$-arm $\mathrm{CT}$ for valvular repair and implantation. Int J Cardiovasc Imaging 2011; 27: 1205-22.

23. Fagan T, Kay J, Carroll J, Neubauer A. 3-D guidance of complex pulmonary artery stent placement using reconstructed rotational angiography with live overlay. Catheter Cardiovasc Interv 2012; 79: 414-21.

24. Berman DP, Khan DM, Gutierrez Y, Zahn EM. The use of threedimensional rotational angiography to assess the pulmonary circulation following cavo-pulmonary connection in patients with single ventricle. Catheter Cardiovasc Interv 2012; 80: 922-30.

25. Fagan TE, Truong UT, Jone PN, et al. Multimodality 3-dimensional image integration for congenital cardiac catheterization. Methodist Debakey Cardiovasc J 2014; 10: 68-76.

26. Truong UT, Fagan TE, Deterding R, et al. Use of rotational angiography in assessing relationship of the airway to vasculature during cardiac catheterization. Catheter Cardiovasc Interv 2015; 86: 1068-77.

27. Aldoss O, Fonseca BM, Truong UT, et al. Diagnostic utility of three-dimensional rotational angiography in congenital cardiac catheterization. Pediatr Cardiol 2016; 37: 1211-21.

28. Starmans NL, Krings GJ, Molenschot MM, et al. Three-dimensional rotational angiography in children with an aortic coarctation. Neth Heart J 2016; 24: 666-74.

29. Surendran S, Waller BR, Elijovich L, et al. Use of 3-D digital subtraction rotational angiography during cardiac catheterization of infants and adults with congenital heart diseases. Catheter Cardiovasc Interv 2017; 90: 618-25.

30. van der Stelt F, Krings GJ, Molenschot MC, Breur JM. Additional value of three-dimensional rotational angiography in the diagnostic evaluation and percutaneous treatment of children with univentricular hearts. Eurolntervention 2018; 14: 637-44.

31. Conijn $\mathrm{M}$, Breur $\mathrm{H}$, Molenschot $\mathrm{M}$, et al. The Y-stenting technique for pulmonary artery bifurcation stenosis: initial results and mid-term outcomes. Int J Cardiol 2018; 268: 202-7.

32. Krings GJ, van der Stelt F, Molenschot MC, Breur JM. Oval stenting in left pulmonary artery stenosis: a novel double balloon technique to prevent airway compression in single ventricle. Eurolntervention 2019 Mar 5. pii: EIJ-D-18-01079. 
33. Lescher S, Gehrisch S, Klein S, Berkefeld J. Time-resolved 3D rotational angiography: display of detailed neurovascular anatomy in patients with intracranial vascular malformations. J Neurointerv Surg 2017; 9: 887-94.

34. Luo H, Meyer-Szary J, Wang Z, et al. Three-dimensional printing in cardiology: current applications and future challenges. Cardiol J 2017; 24: 436-44.

35. Sabiniewicz R, Meyer-Szary J, Potaż P, et al. Melody valve implantation pre-procedural planning using custom-made 3D printed model of the region of interest. Adv Interv Cardiol 2018; 14: 210-1.

36. Garg G, Tyagi H, Radha AS. Transcatheter closure of sinus venosus atrial septal defect with anomalous drainage of right upper pulmonary vein into superior vena cava: an innovative technique. Catheter Cardiovasc Interv 2014; 84: 473-7.

37. Riahi M, Velasco Forte MN, Byrne $\mathrm{N}$, et al. Early experience of transcatheter correction of superior sinus venosus atrial septal defect with partial anomalous pulmonary venous drainage. Eurolntervention 2018; 14: 868-76.

38. Diab K. Review of PICS-AICS 2018 in Las Vegas. Congenital Cardiol Today 2018; 16: 8-12.

39. Hijazi ZM. The Pediatric and Adult Interventional Cardiac Symposium (PICS/AICS) $21^{\text {st }}$ Annual Meeting - Las Vegas, Nevada, September 5-8, 2018. Structural Heart Dis 2018; 4: 114-206.

40. Goreczny S, Hijazi ZM, Qureshi SA, et al. Molding the shape of congenial and structural interventional cardiology: interviews with directors of major congresses. Cardiol Young 2019; 29: 1009-15.

41. Goreczny S, Zablah J, McLennan D, et al. Multi-modality imaging for percutaneous pulmonary valve implantation - getting serious about radiation and contrast reduction. Adv Interv Cardiol 2019; 15: 110-5.

42. Bruckheimer E, Rotschild C. Holography for imaging in structural heart disease. Eurolntervention 2016; 12: X81-4.

43. Rymuza B, Grodecki K, Kamiński J, et al. Holographic imaging during transcatheter aortic valve implantation procedure in bicuspid aortic valve stenosis. Kardiol Pol 2017; 75: 1056.

44. Silva JNA, Southworth M, Raptis C, Silva J. Emerging applications of virtual reality in cardiovascular medicine. JACC Basic Transl Sci 2018; 3: 420-30.

45. Goreczny S, Dryzek P, Moszura T. Novel 3-dimensional image fusion software for live guidance of percutaneous pulmonary valve implantation. Circ Cardiovasc Interv 2016; 9: e003711.

46. Goreczny S, Dryzek P, Moszura T. Use of pre-intervention imaging with a novel image fusion software for guidance of cardiac catheterisation in a patient with pulmonary atresia and major aortopulmonary collaterals. Cardiol Young 2016; 26: 1438-40.

47. Goreczny S, Dryzek P, Moszura T. Stent implantation to ductus arteriosus in a patient with interrupted aortic arch guided by CT image overlay. Cardiol Young 2017; 6: 1229-31.

48. Goreczny S, Dryzek P, Morgan GJ, et al. Novel three-dimensional image fusion software to facilitate guidance of complex cardiac catheterization. Pediatr Cardiol 2017; 38: 1133-42.

49. Goreczny S, Dryzek P, Moszura T, et al. 3D image fusion for live guidance of stent implantation in aortic coarctation - magnetic resonance imaging and computed tomography image overlay enhances interventional technique. Adv Interv Cardiol 2017; 13: 269-72.

50. Ehret N, Alkassar M, Dittrich S, et al. A new approach of three-dimensional guidance in paediatric cath lab: segmented and tessellated heart models for cardiovascular interventions in CHD. Cardiol Young 2018; 28: 661-7.
51. Góreczny S, Dryżek P, Moszura T, et al. Magnetic resonance and computed tomography imaging fusion for live guidance of percutaneous pulmonary valve implantation. Adv Interv Cardiol 2018; 14: 413-21.

52. Nordmeyer J, Kramer P, Berger F, Schubert S. Successful exclusion of an aortic aneurysm with a novel PTFE-tube covered cobalt-chromium stent in a pediatric patient with native coarctation of the aorta. Catheter Cardiovasc Interv 2018; 92: 930-4.

53. Sandoval JP, Aristizabal G, Zabal-Cerdeira C. Aortic stent implantation using live 3-dimensional image fusion guidance. Rev Esp Cardiol (Engl Ed) 2018; 71: 750.

54. Góreczny S, Podgórski M, Moszura T. Multimodality imaging for no contrast trans-catheter closure of an arteriovenous fistula. Cardiol Young 2019; 29: 695-6.

55. Assink N, Izamis M, Nempont O, et al. Feasibility of fully automated motion compensated overlay for transcatheter aortic valve implantation. Structural Heart Disease 2018; 4: 207-11.

56. Ribeiro J, Braga P, Gama V. New catheter, wide angle imaging, 3D intracardiac echocardiography. Rev Esp Cardiol (Engl Ed) 2018; 71: 293.

57. Schäfer M, Morgan GJ, Mitchell MB, et al. Impact of different coarctation therapies on aortic stiffness: phase-contrast MRI study. Int J Cardiovasc Imaging 2018; 34: 1459-69.

58. Goreczny S, Moszura T, Lukaszewski M, et al. Three-dimensional image fusion of precatheter CT and MRI facilitates stent implantation in congenital heart defects. Rev Esp Cardiol (Engl Ed) 2019; 72: 512-4. 